\title{
The Analysis of the Natural Smoke Filling Times in an Atrium
}

\author{
Guan-Yuan Wu and Ruu-Chang Chen \\ Department of Fire Science, Central Police University, 56 Shu-jen Roud., Ta-kang, Kwei-san, Tao-yuan 333, Taiwan \\ Correspondence should be addressed to Guan-Yuan Wu, una210@mail.cpu.edu.tw
}

Received 5 July 2010; Accepted 19 September 2010

Academic Editor: Ishwar Puri

Copyright ( 2010 G.-Y. Wu and R.-C. Chen. This is an open access article distributed under the Creative Commons Attribution License, which permits unrestricted use, distribution, and reproduction in any medium, provided the original work is properly cited.

This paper presents an investigation on the scenarios of the natural smoke filling times in an atrium due to a located floor fire. Based on the Heskestad's correlation, the heat release rate and the effective height of the fire source were transformed into an equation associated with the diameter and perimeter of the fire source. Neglecting the thermal effect for heat release due to relatively small temperature rise in the atrium and applying the assumption of mass conservation, the height of smoke layer interface can be derived. In this study, the various plume models such as McCaffrey's correlation, Zukoski's correlation, Thomas's correlation and NFPA 92B's correlation are considered with both steady fire and unsteady fire situations. The comparisons between the theoretical results and the experimental data were also made and discussed.

\section{Introduction}

Commercial buildings such as spacious shopping malls and hotels have become popular in our everyday lives. Most of the architecture, furniture, and interior hardware are made of synthetic materials such as chemical fabric and plastic. When they burn, considerable amount of toxic and heavy smoke are generated. As the fire reaches the fully developed fire, flame and smoke develop rapidly which makes the occupant escape even more difficult. Therefore, the smoke filling period of enclosure fires is of concern for many fire safety analysis and design purposes, particularly those related to available safe egress time (ASET) and smoke management in large spaces [1-3].

Thomas et al. [4], Zukoski et al. [5], McCaffrey [6], and Heskestad [7] have developed many equations with regards to smoke producing rate based on fire plume model or experimental data. Many of them are widely applied to the zone model. For example, CFAST [8] computer simulation software used two-layer zone model (upper hot layer and lower cold layer) and McCaffrey's correction to calculate the plume entrainment rate [9]. However, different entrainment rates were obtained under same fire source because some equations were obtained by theoretical research and others by experimental results. Different entrainment rates consequently lead to different smoke filling predictions and smoke control and thereby add more uncertainties to fire prevention design of the buildings.

Recently, the issue of smoke layer descent in large space buildings has received great attention worldwide. For example, a series of full-scale burning tests were studied at the PolyU/USTC Atrium constructed at the campus of University of Science and Technology of China (USTC), Hefei, China [10-12]. Chung and Tung [13] presented a modified smoke filling time calculation method with sprinkler effect in which a full-scale experimental program was conducted to evaluate the feasibility of the application of the model. The fire plume model was the major approach dealing with smoke layer descent issue. It is well known that when fire breaks out from the center of the floor in an unventilated room, hot smoke plume rises to the ceiling by buoyancy force. When the smoke plume rises, relatively cool ambient air is entrained into the plume to reduce its temperature. However, this entrainment increases the mass flow rate of the contaminated air. When the smoke plume reaches the ceiling, momentum of the plume has an effect of a jet, spreading the smoke over the entire ceiling. In the meantime, it also dilutes and cools down the burning products. Therefore, the fire plume is a convective cylinder above the fire source, and its structure is determined by the interaction between uprising plume and ambient flow [14]. 


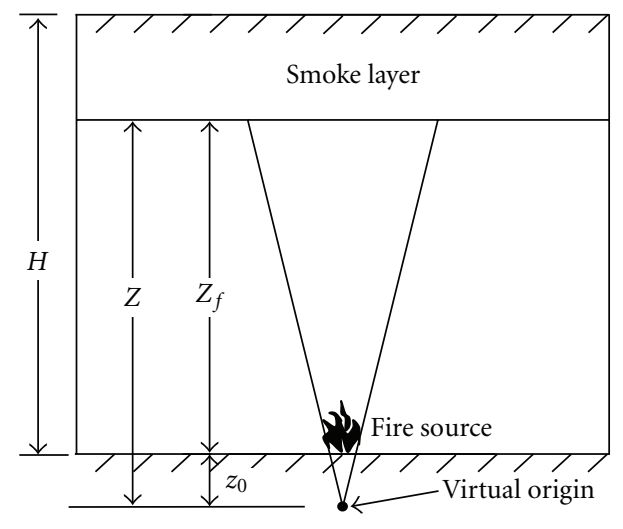

Figure 1: The two-layer zone model.

This paper presents a detailed investigation of the natural smoke filling times in an atrium duo to a centrally located floor fire through both theoretical simulations and physical experiments. In order to understand the correlation between smoke layer descent and time under different fire source scenarios, Heskestad's correction of heat release rate, size, and height of fire source was transformed into an equation of fire source's diameter and its perimeter. Using the twolayer zone model and applying the assumption of mass conservation, the results of the smoke layer interface height and time for both steady fire and unsteady fire can be calculated. The theoretical predictions including McCaffrey's correction, Zukoski's correction, Thomas's correction, and NFPA-92B's correction were plotted. In this study, one fullscale burning test was performed in an atrium constructed in the State Key Laboratory of Fire Science of USTC Hefei, Anhui, China, as a collaboration project with Architecture Research Institute, Taiwan [15]. The other experiment was performed in a large-spaced building by Fire Prevention Laboratory in Guei-Jen Tainan [16]. Finally, comparison between theoretical predictions of smoke filling time using various scenarios was made and discussed.

\section{Proposed Model}

In order to simplify the mathematical calculation, the twolayer model developed previously is used, and the simple buoyant plume is based on a virtual origin as shown in Figure 1. The buoyant plume flow would be axisymmetric and extend vertically to a height where the buoyancy force has become too weak to resist the viscous drag.

2.1. Design Fires. A design fire is generally used to simulate real fire situation and describe the heat release rate for burning. There are two types of fire source: steady fire with constant heat release rate and unsteady fire with the heat release rate varying with time.

Steady Fires. In general, a steady fire assumes that the heat release rate of the fire source is constant. Although the heat release rates of most construction materials are known, the combination of different material makes the estimate of
TABLE 1: Fire growth rate for $t$-square fires [3].

\begin{tabular}{lcc}
\hline Fire growth rate & Value of $\alpha\left(\mathrm{kW} / \mathrm{s}^{2}\right)$ & Value of $t_{g}(\mathrm{sec})$ \\
\hline Slow & 0.00293 & 600 \\
Medium & 0.01172 & 300 \\
Fast & 0.0469 & 150 \\
Ultra fast & 0.1876 & 75 \\
\hline
\end{tabular}

the heat release rate rather difficult. Idealization of the fire source does not reflect the real fire situation. However, it simplifies the description and exploration of the fire source. The adoption of steady fire is explicit and conservative in fire source design application.

Unsteady Fires. In the initial stage of a fire, the air flows thoroughly, and the heat release rate is determined by the form, quantity, and shape of the burning product. Rough estimation on the velocity of the smoke layer descent can be made using steady fire assumption. As a fact, burning progresses by time, and thereby the scale of the fire source changes the amount of the smoke generated and the heat release rate. The growth rate of a design fire is characterized by a parabolic curve known as a $t$-square fire such that the heat release rate is proportional to time squared. In this study, the $t$-square fire defined by NFPA 92B [3] is adopted, and its equation is as follows:

$$
\dot{Q}=\alpha \cdot t^{2}\left(=1055\left(\frac{t}{t_{g}}\right)^{2}\right),
$$

where $Q$ is the heat release rate of the fire source $(\mathrm{kW}) ; \alpha$ is the fire growth coefficient $\left(\mathrm{kW} / \mathrm{s}^{2}\right), t$ is time $(\mathrm{sec})$, and $t_{g}$ is growth time (sec).

The numerical value of $t_{g}$ is the time to for fire to reach a size of $1055 \mathrm{~kW}$. It is well known that $t$-square fire is divided into four modes by its growth velocity: ultrafast, fast, medium, and slow. The fire intensity coefficient and growth time for four modes are presented in Table 1 [3].

2.2. The Diameter and Perimeter of the Fire Sources. Under normal atmospheric conditions, the correction equation of fire source and heat release rate as proposed by Heskestad [7] is

$$
L=-1.02 \cdot D_{f}+0.23 \cdot \dot{Q}^{2 / 5},
$$

where $L$ is the height of the fire source $(\mathrm{m}) ; D_{f}$ is the diameter of the fire source $(\mathrm{m}) . \dot{Q}$ is the heat release rate $(\mathrm{kW})$. The range in $\dot{Q}^{2 / 5} / D_{f}$ for which (2) is known to be approximately valid is 7 to $700 \mathrm{~kW}^{2 / 5} / \mathrm{m}$.

The diameter of the steady fire source can be calculated from (2)

$$
D_{f}=0.2255 \cdot \dot{Q}^{2 / 5}-0.9804 \cdot L .
$$

For a noncircular fire source, the effective diameter of the steady fire source can be obtained as $\pi \cdot D_{f}^{2} / 4=$ area of fire source [17]. In this study, a square-shaped fire source is 
considered, and the perimeter $P_{f}$ of the fire source can be calculated as

$$
\pi \cdot \frac{D_{f}^{2}}{4}=\left(\frac{P_{f}}{4}\right)^{2}
$$

For steady fire, (4) can also be expressed as:

$$
P_{f}=3.5449 D_{f}
$$

Substituting (3) into (5), the perimeter of the steady fire source is obtained

$$
P_{f}=0.7994 \dot{Q}^{2 / 5}-3.4754 L .
$$

Substituting (1) into (5) and (6), the diameter and perimeter of the unsteady fire source can be obtained, respectively, as

$$
\begin{aligned}
& D_{f}=0.2255 \alpha^{2 / 5} t^{4 / 5}-0.9804 L, \\
& P_{f}=0.7994 \alpha^{2 / 5} t^{4 / 5}-3.4754 L .
\end{aligned}
$$

2.3. The Mass Flow Rate. Based on the two-layer zone mode [12], the rate of change of the smoke layer mass can be expressed as

$$
\frac{d m_{s}}{d t}=\dot{m}
$$

where $m_{s}$ is the smoke layer mass, $\dot{m}$ is the entrainment rate $(\mathrm{kg} / \mathrm{s})$. Based on the assumption of mass conservation, the smoke layer mass can be expressed in terms of the smoke density $\rho_{s}$, floor area of the atrium $A$, the smoke layer interface height above the fire source $Z_{f}$ and the ceiling height above the fire source $H$ as in Figure 1which gives

$$
m_{s}=\rho_{s} A\left(H-Z_{f}\right) .
$$

Neglecting the thermal effect for heat release due to relatively small temperature rise in the atrium and substituting (10) into (9), the mass flow rate can be expressed as

$$
\dot{m}=-\rho_{s} A \frac{d Z_{f}}{d t} .
$$

\section{The Correction of the Fire Plume}

Whether there is sufficient time to allow evacuation before smoke layer interface descends is a critical criterion evaluating safe space partition. By formulating the relationship between time and smoke layer interface descent, the time when the smoke layer interface descends to certain height which could impede evacuation can be predicted. The following equations are based on the equations of the entrainment rate, the heat release rate, and the smoke layer interface height found by McCaffrey, Zukoski, Thomas, and NFPA 92B.
3.1. McCaffrey's Correction. By analyzing experimental results of the temperature and upward velocity, McCaffrey has identified three major regions: continuous flame region, intermittent flame region, and smoke plume region [6]. The spill plume equations were obtained using methane flame with heat release rate of $14.4,21.7,33.0,44.9$, and $57.5 \mathrm{KW}$. It should be noted that in McCaffrey correlation equations, plume properties are assumed to be independent of fuel and only dependent on heat release rate $\dot{Q}[9]$. The correction of the smoke plume region is given by

$$
\dot{m}=0.124\left(\frac{Z_{f}}{\dot{Q}^{2 / 5}}\right)^{1.892} \dot{Q} \quad \text { for } 0.20 \leq \frac{Z_{f}}{\dot{Q}^{2 / 5}} .
$$

Defining the smoke layer generation rate as the mass flow rate of plume into upper layer and combining (11) and (12), the correction equation of the smoke plume yields

$$
Z_{f}^{-1.895} d Z_{f}=-0.124 \rho_{s}^{-1} A^{-1} \dot{Q}^{0.2420} d t .
$$

Steady Fire. For steady fire, $\dot{Q}$ is treated as a constant. Integrating (13) and using the initial condition $\left(\left.\mathrm{Z}\right|_{t=0}=H\right)$, the height of the smoke layer in this case can be obtained as

$$
Z_{f}=\left(0.1110 \rho_{s}^{-1} A^{-1} \dot{Q}^{0.2420} t+H^{-0.895}\right)^{-1.1173} .
$$

Unsteady Fire. Substituting (1) into (14), then the height of the smoke layer $Z_{f}$ can be obtained by the integral of $t$ and $Z_{f}$.

$$
Z_{f}=\left(0.07479 \rho_{s}^{-1} A^{-1} \alpha^{0.2420} t^{1.4840}+H^{-0.895}\right)^{-1.1173} .
$$

3.2. Zukoski's Correction. To obtain a correction for axisymmetric plumes for far field, experimental data were correlated and developed by Zukoski et al. [5] as

$$
\dot{m}=0.076 \dot{Q}^{1 / 3}\left(Z_{f}+Z_{0}\right)^{5 / 3}=0.076 \dot{Q}^{1 / 3} Z^{5 / 3},
$$

where $Z$ is the smoke layer interface height above the virtual fire source. For steady fire, where $\dot{Q}$ is treated as a constant, then the value of $Z_{0}$ will be a constant, and the differential value of $d Z / d t$ shall be equal to $d Z_{f} / d t$. Further, while an atrium and a lower value of $\dot{Q}$ are considered for an unsteady fire, the value of $Z_{f}$ shall be much higher than that of $Z_{0}$, and this result is yielded to $d Z_{f} / d t \approx d Z / d t$. Therefore, the mass flow rate in this model can be expressed as

$$
\dot{m}=-\rho_{s} A \frac{d Z_{f}}{d t} \cong-\rho_{s} A \frac{d Z}{d t} .
$$

Substituting (16) into (17), the correction can be rewritten as

$$
Z^{-5 / 3} d Z=-0.076 \rho_{s}^{-1} A^{-1} \dot{Q}^{1 / 3} d t .
$$

The virtual origin of the fire source, $Z_{0}$ was proposed by Cetegen et al. [18] as

$$
\begin{aligned}
D_{f}^{-2 / 5} \dot{Q}<1105, & Z_{0}=0.01\left(\frac{\dot{Q}}{D_{f}}\right)^{2 / 3}-C_{f} D_{f}, \\
D_{f}^{-2 / 5} \dot{Q} \geq 1105, & Z_{0}=0.066 \cdot \dot{Q}^{2 / 5}-C_{f} D_{f},
\end{aligned}
$$

where $C_{f}=0.5$ for fire source located at the floor; $C_{f}=0.8$ for fire located above the floor. 
Steady Fire. Integrating (18) and substituting the initial condition, the height of the smoke layer $Z$ can be easily derived and shown as

$$
Z=\left(0.0507 \rho_{s}^{-1} A^{-1} \dot{Q}^{1 / 3} t+H^{-2 / 3}\right)^{-3 / 2} .
$$

Here, $Z_{f}$, which is the actual height of the smoke layer from the floor and is equal to $Z-Z_{0}$, can be expressed as

$$
Z_{f}=\left(0.0507 \rho_{s}^{-1} A^{-1} \dot{Q}^{1 / 3} t+H^{-2 / 3}\right)^{-3 / 2}-Z_{0}
$$

Assuming that the fire is located at the floor $\left(C_{f}=0.5\right), Z_{f}$ can be obtained by combining (3), (19), and (21)

$$
\begin{aligned}
& \left(0.2255 \dot{Q}^{2 / 5}-0.9804 L\right)^{-2 / 5} \dot{Q}<1105, \\
Z_{f}= & \left(0.0507 \rho_{s}^{-1} A^{-1} \dot{Q}^{1 / 3} t+H^{-2 / 3}\right)^{-3 / 2} \\
& +0.1128 \dot{Q}^{2 / 5}-0.4902 L \\
& -0.01\left(0.2255 \dot{Q}^{2 / 5}-0.9804 L\right)^{-2 / 3} \dot{Q}^{2 / 3} \\
& \left(0.2255 \dot{Q}^{2 / 5}-0.9804 L\right)^{-2 / 5} \dot{Q} \geq 1105, \\
Z_{f}= & \left(0.0507 \rho_{s}^{-1} A^{-1} \dot{Q}^{1 / 3} t+H^{-2 / 3}\right)^{-3 / 2} \\
& +0.0468 \dot{Q}^{2 / 5}-0.4902 L .
\end{aligned}
$$

Unsteady Fire. Substituting (1) into (17) and integrating (17) with respect to time and height, respectively, the $Z_{f}$ can be expressed as

$$
Z_{f}=\left(0.0304 \rho_{s}^{-1} A^{-1} \alpha^{1 / 3} t^{5 / 3}+H^{-2 / 3}\right)^{-3 / 2}-Z_{0} .
$$

The actual height of the smoke layer $Z_{f}$ would be determined by assuming $C_{f}=0.5$ and combining (8), (19), and (23)

$$
\begin{aligned}
& \left(0.2255 \alpha^{2 / 5} t^{4 / 5}-0.9804 L\right)^{-2 / 5} \alpha t^{2}<1105, \\
Z_{f}= & \left(0.0304 \rho_{s}^{-1} A^{-1} \alpha^{1 / 3} t^{5 / 3}+H^{-2 / 3}\right)^{-3 / 2} \\
& +0.1128 \alpha^{2 / 5} t^{4 / 5}-0.4902 L \\
& -0.01\left(0.2255 \alpha^{2 / 5} t^{4 / 5}-0.9804 L\right)^{-2 / 3} \alpha^{2 / 3} t^{4 / 3}, \\
& \left(0.2255 \alpha^{2 / 5} t^{4 / 5}-0.9804 L\right)^{-2 / 5} \alpha t^{2} \geq 1105, \\
Z_{f}= & \left(0.0304 \rho_{s}^{-1} A^{-1} \alpha^{1 / 3} t^{5 / 3}+H^{-2 / 3}\right)^{-3 / 2} \\
+ & 0.0468 \alpha^{2 / 5} t^{4 / 5}-0.4902 L .
\end{aligned}
$$

3.3. Thomas's Correction. By observing the continuous flame region and near field,Thomas et al. [4] discovered that the mass flow rate of the plume is independent to the heat release rate and it is related to the perimeter of the fire, $P_{f}$, and the height above the fire source, $Z_{f}$. The mass flow rate can be expressed $[4,9]$ as

$$
\dot{m}=0.188 Z_{f}^{-3 / 2} P_{f}
$$

Substituting (25) into (11), the correction equation of the smoke plume yields

$$
Z_{f}^{-3 / 2} d Z_{f}=-0.188 \rho_{s}^{-1} A^{-1} P_{f} d t
$$

Steady Fire. For steady fire, substituting (5) and (3) into (26) and solving the initial problem with $\left.Z_{f}\right|_{t=0}=H$, the height of the smoke layer $Z_{f}$ can be expressed as

$$
Z_{f}=\left[\rho_{s}^{-1} A^{-1} t\left(0.0754 \dot{Q}^{2 / 5}-0.3267 L\right)+H^{-1 / 2}\right]^{-2.0} .
$$

Unsteady Fire. For unsteady fire, substituting (8) into (26) and integrating (26) with respect to time and height, the correlation of smoke layer interface height $Z_{f}$ and time $t$ can be expressed as

$$
Z_{f}=\left[\rho_{s}^{-1} A^{-1} t\left(0.0417 \alpha^{2 / 5} t^{4 / 5}-0.3267 L\right)+H^{-1 / 2}\right]^{-2.0} .
$$

It should be noted that Thomas' equation was derived from experiments under steady fire. When being substituted into the density of smoke layer $\rho_{s}$, the height of fire source $L$, cross-sectional area of the building $A$, and the height of the building $H$, in (28) yields an unrealistic result which the interface height of the smoke layer exceeds the height of the building. As a result, Thomas' equation under unsteady fire scenario will be not discussed here in this paper.

\subsection{NFPA-92B's Correction}

Steady Fire. For steady fire, the interface height of the smoke layer $Z_{f}$ was suggested by NFPA 92B [3] as

$$
Z_{f}=\left[1.11-0.28 \ln \left(A^{-1} H^{2 / 3} \dot{Q}^{1 / 3} t\right)\right] H,
$$

where $A$ is the cross section area of the smoke filling space $\left(\mathrm{m}^{2}\right), H$ is the height of the ceiling $(\mathrm{m}) ; \dot{Q}$ is the heat release rate under steady fire $(\mathrm{kW}) ; t$ is the time $(\mathrm{sec})$. Equation (29) applies when the following limitation conditions are satisfied: (1) uniform cross-sectional area with respect to height; (2) $A / H^{2}$ ratios in the range from 0.9 to 1.0 ; (3) steady fires; (4) $Z / H>0.2$; (5) no smoke exhaust operating.

Unsteady Fire. For unsteady $t$-square fires, NFPA 92B proposed the smoke layer calculation as

$$
Z_{f}=\left[0.91\left(A^{-3 / 5} H^{2 / 5} t_{g}^{-2 / 5} t\right)^{-1.45}\right] H
$$

where $t_{g}$ is the growth time (sec). The following limitation conditions need to be taken into consideration when using (30): (1) uniform cross-sectional area with respect to height; (2) $A / H^{2}$ ratios in the range from 1 to 23 ; (3) unsteady fires; (4) $\mathrm{Z} / \mathrm{H}>0.2$; (5) no smoke exhaust operating. 
It is concluded that (29) and (30) apply to cubic buildings with relatively uniformed length, width, and height; the height of the smoke layer interface is measured larger than 0.2 times the ceiling height. It will be well known that the scenarios of the combustion in most large space buildings will not meet these above requirements.

\section{Full-Scale Experiment on Smoke Layer Descent}

A smoke control technical specification project for tall atrium in open- spaced buildings was commissioned by Architecture Research Institute, Taiwan and in which a fullscale fire experiment was carried out by cooperation with State Key Laboratory of Fire Science of USTC Hefei, Anhui, China [15]. Experiments are performed in a large openspaced site of length $22.4 \mathrm{~m}$, width $11.9 \mathrm{~m}$, and height $27.0 \mathrm{~m}$. With both natural ventilation and mechanical smoke exhaust system closed, a steady fire oil burner with heat release rate of $2.0 \mathrm{MW}$ was placed to measure the thermocouple temperature of the smoke layer under natural smoke filling scenario. Experimental results of the smoke layer interface height and time and CFAST computer simulation were obtained.

In addition, a special experiment was performed in a large-spaced building by Fire Prevention Laboratory in Guei-Jen, Tainan [16]. The dimension of the laboratory is $41 \mathrm{~m} \times 23 \mathrm{~m}$ with a height of $23 \mathrm{~m}$. This experiment was executed on a full-scale basis, the aim is to compare and analyze the functions in terms of both prescription and performance-based design for smoke control. By adjusting the amount of smoke exhaust, the velocity of smoke descent and the smoke exhaust performance were evaluated. With both natural ventilation and smoke exhaust equipment closed, the interface height of the smoke layer and time were obtained when oil burners with heat release rate of 3.0 MW and 5.0 MW were placed under natural smoke filling scenario.

\section{Results and Discussions}

The interface height calculation of the smoke layer by three spill plume models under both steady fire and unsteady fire scenarios was shown in the above section. Under steady fire scenario, they were compared with the results of two research projects for large and open space buildings commissioned by Architecture Research Institute of Ministry of Internal Affairs, Taiwan. Under unsteady fire scenario, they were compared with NFPA92B prediction.

5.1. Steady Fire Scenarios. When being inserted with known space dimension, fire source height, smoke layer density, and heat release rate, three spill plume models enable the calculation of the interface height of the smoke layer and time with no aid from the fire source simulation software. It is should be noted that only the equation in smoke plume region was adopted among three regions of McCaffrey

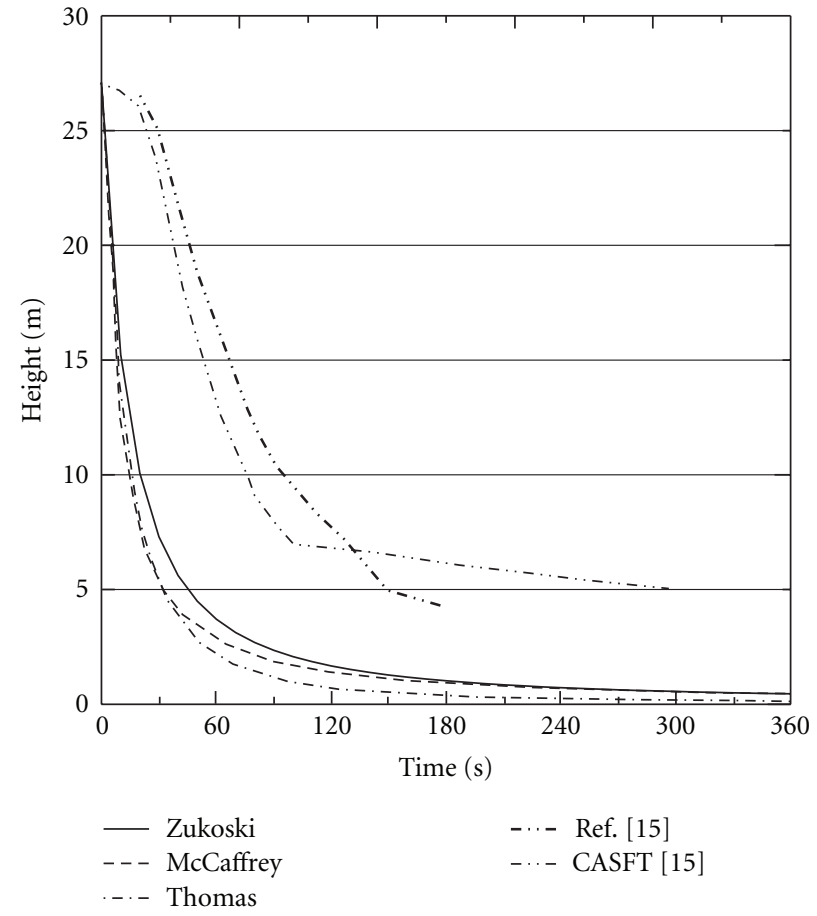

FIGURE 2: The interface height of smoke layer under 2.0 MW natural smoke filling scenario.

model. The physical parameters of this system are given as research project for tall atrium in open-spaced buildings is as

$$
\begin{gathered}
\dot{Q}=2.0 \mathrm{MW}, \quad \rho_{s}=0.4577 \mathrm{~kg} / \mathrm{m}^{3}, \\
L=1.8 \mathrm{~m}, \quad A=266.56 \mathrm{~m}^{2}, \quad H=27.0 \mathrm{~m} .
\end{gathered}
$$

The result of the interface height in this study and the results derived by experiment and CFAST [15] are shown in Figure 2. The results show that Zukoski, McCaffrey, and Thomas models yield similar results to this project [15] and CFAST simulation. However, the interface height of the three models descends much faster than that of the research project and CFAST simulation. In other words, the smoke flow rates of the project and CFAST simulation are lower.

Because the dimensions of the laboratories in $[15,16]$ do not accord with the NFPA 92B conditions, an additional experimental grid with $25 \mathrm{~m}$ in width, length, and height was set up. The results of NFPA 92B code, McCaffrey, Zukoski, and Thomas model predictions under heat release rate of 2.0 MW and fire source height of $1.8 \mathrm{~m}$ were depicted in Figure 3. The results present that McCaffrey, Zukoski, and Thomas models have produced results which are similar to NFPA 92B prediction for 2.0 MW steady fire. However, the interface height of smoke layer predicted by NFPA $92 \mathrm{~B}$ is the highest, and it started to descend dramatically at 240 second and fell below the other three models at 300 second. From Figures 2 and 3, we can see that McCaffrey, Zukoski, Thomas model, and NFPA 92B yield quite similar results in calculating interface height of smoke layer for $\dot{Q}=2.0 \mathrm{MW}$.

Figures 4 and 5 show the interface height of the smoke layer of the experimental project [16] carried out in large 

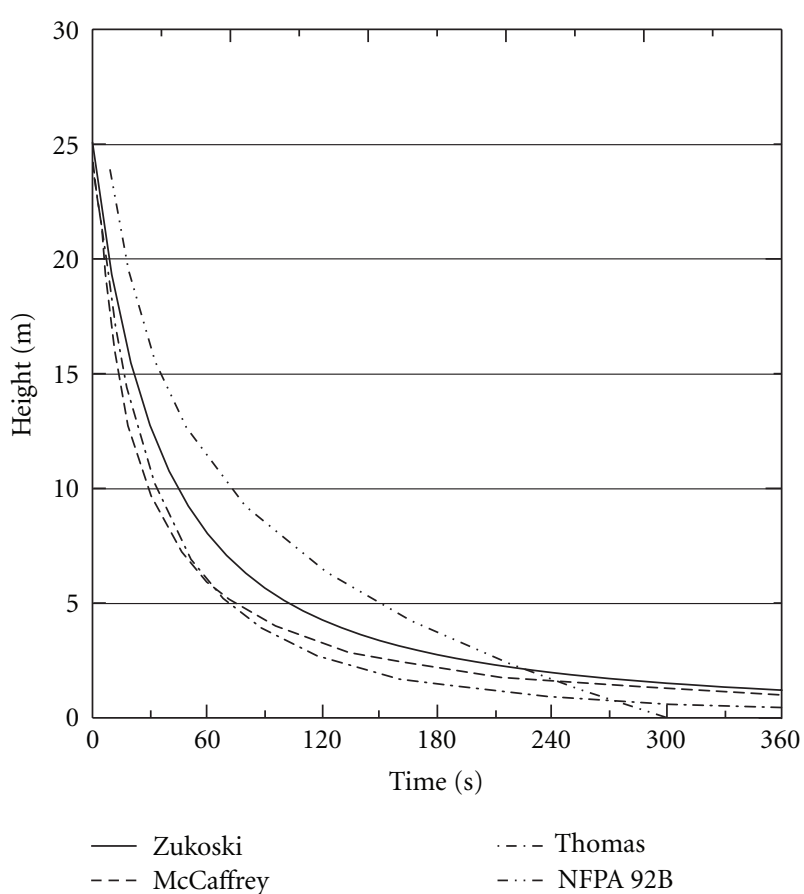

\section{-. - Thomas}

-..- NFPA 92B

FIGURE 3: The interface height of smoke layer compared with NFPA 92B with heat release rate of $2.0 \mathrm{MW}$ under steady fire.

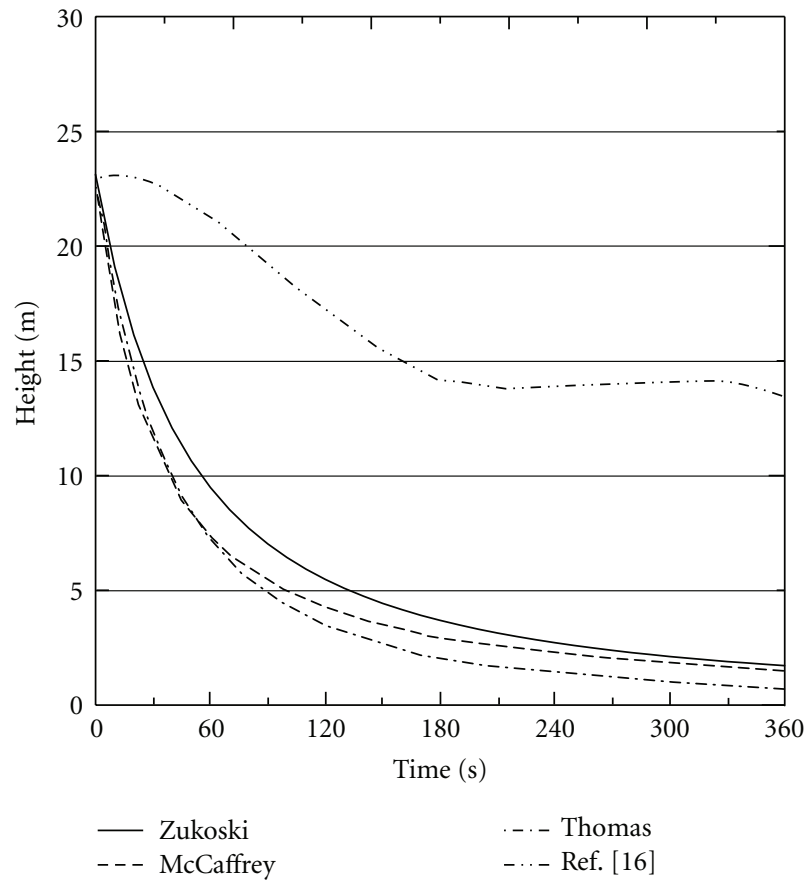

FIGURE 4: The interface heights of smoke layer for 3.0 MW steady fire.

space buildings with dimension of $41 \mathrm{~m} \times 23 \mathrm{~m}$ and a height of $23 \mathrm{~m}$. The heat release rates are 3.0 MW and 5.0 MW, and fire source heights are $2.1 \mathrm{~m}, 2.4 \mathrm{~m}$, and $2.7 \mathrm{~m}$, respectively. From Figures 2-5, it is observed that McCaffrey, Zukoski, and Thomas models agree well with each other under different heat release rate assumptions, and they produce

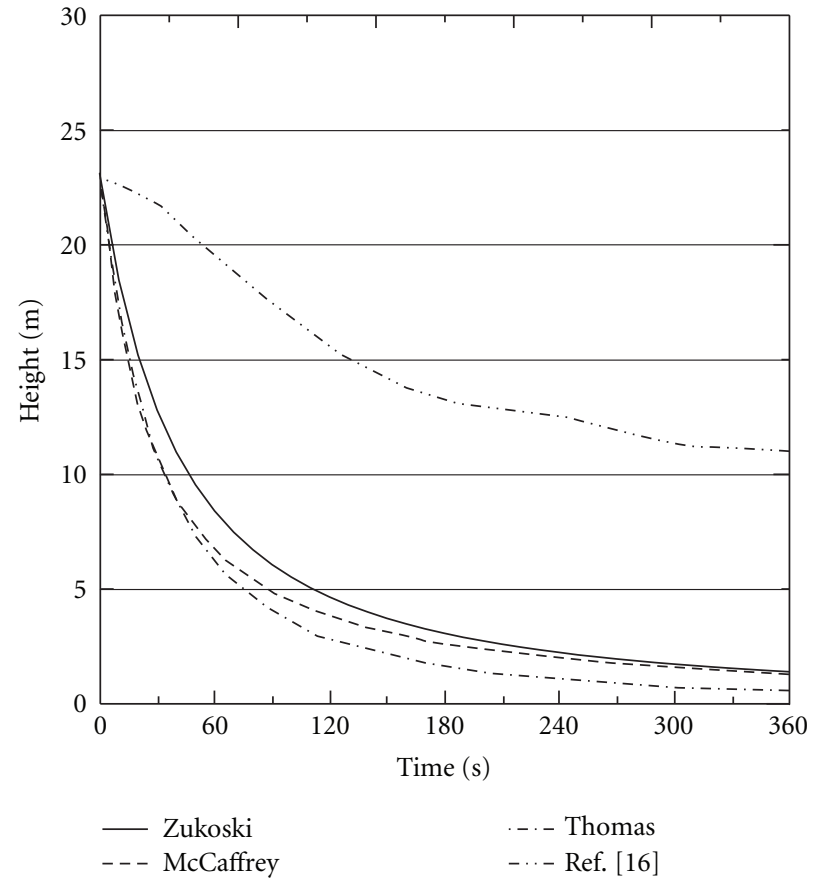

FIGURE 5: The interface heights of smoke layer for 5.0 MW steady fire.

relatively similar results to the project [16] when heat release rate is $2.0 \mathrm{MW}$. For heat release rate above $3.0 \mathrm{MW}$, the experimental result [16] is much higher than those of the three models. It is presumed that the theoretical heat release rate of all three models ranging under $750 \mathrm{KW}$ (even under $57.5 \mathrm{KW}$ for McCaffrey model) and their using of different heat source other than oil have caused the large deviation from the project [16] and CFAST simulation under higher heat release rate assumption.

5.2. Unsteady Fire Scenarios. Figure 6 demonstrates the interface heights of smoke layer simulated by McCaffrey, Zukoski, CFAST, and in [15] experiment with ultra fast firegrowth coefficient value of $0.1876\left(\mathrm{~kW} / \mathrm{s}^{2}\right)$ and maximum fire source of $2.0 \mathrm{MW}$ for unsteady fire. Figure 6 also shows that the interface height curves in Zukoski and McCaffrey plume models descend quickerthan in [15] experiment and CFAST prediction. From Figures 2 and 6 , it is seen that the prediction of the plume models descends quicker than the experimental results for both steady and unsteady fire. The smoke layer interface descends quicker under steady fire, which may be caused by the fact that the steady fire source reaches the default heat release rate right after ignition while it takes time for unsteady fire source to approach the default heat release rate.

It is noted that the dimension of laboratories in $[15,16]$ laboratories do not accord with NFPA 92B application range. In this study, experiments were performed using McCaffrey and Zukoski equation in a $25 \mathrm{~m} \times 25 \mathrm{~m} \times 25 \mathrm{~m}$ space with heat release rate of $2.0 \mathrm{MW}$ and fire source height of $1.8 \mathrm{~m}$. The interface height of the smoke layer of the experiments 

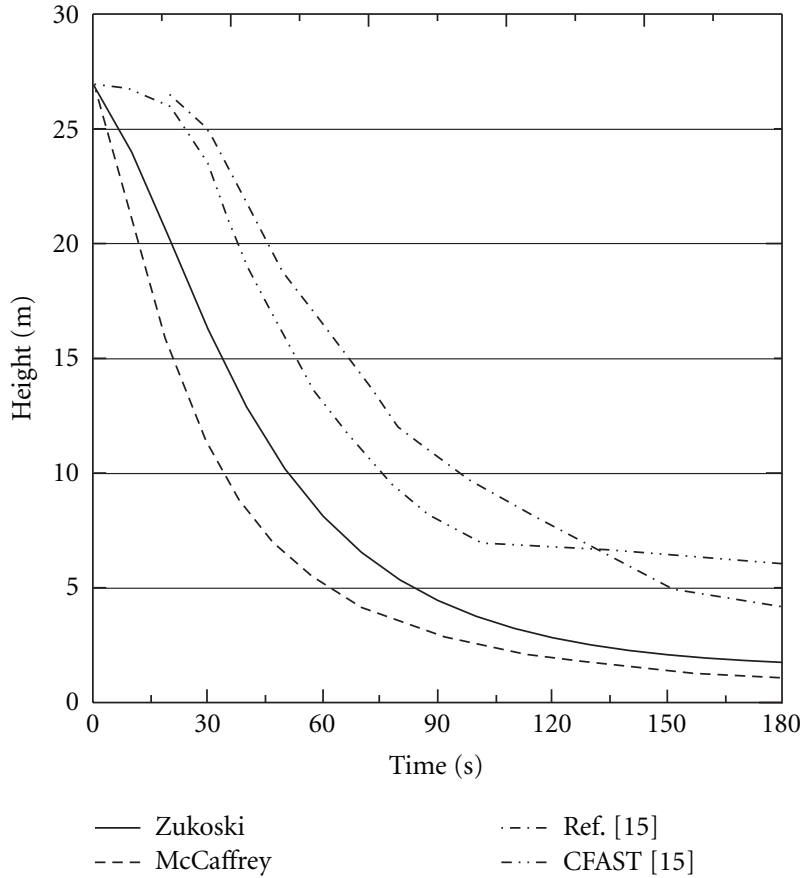

Figure 6: Comparisons of interface height of smoke layer for 2.0 MW unsteady fire.

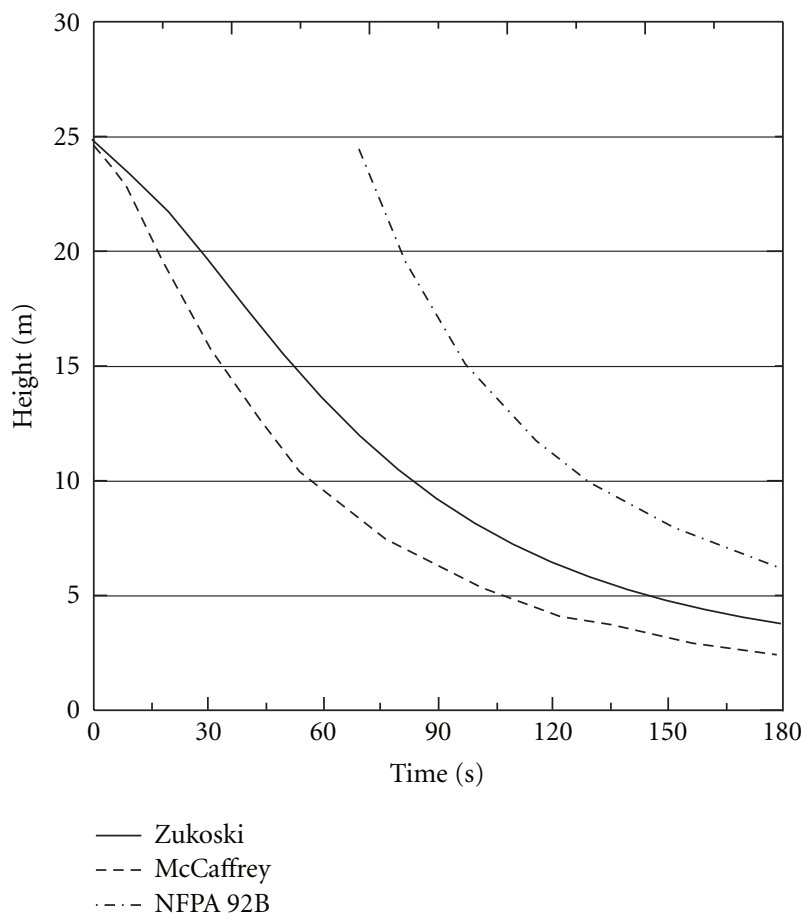

FIGURE 7: The interface height of smoke layer compared with NFPA $92 \mathrm{~B}$ with heat release rate of $2.0 \mathrm{MW}$ under unsteady fire.

was compared with that of NFPA 92B and presented in Figure 7. It is seen that McCaffrey and Zukoski curves are distant from NFPA 92B at the beginning of the fire. However, three curves tend to converge after two minutes.

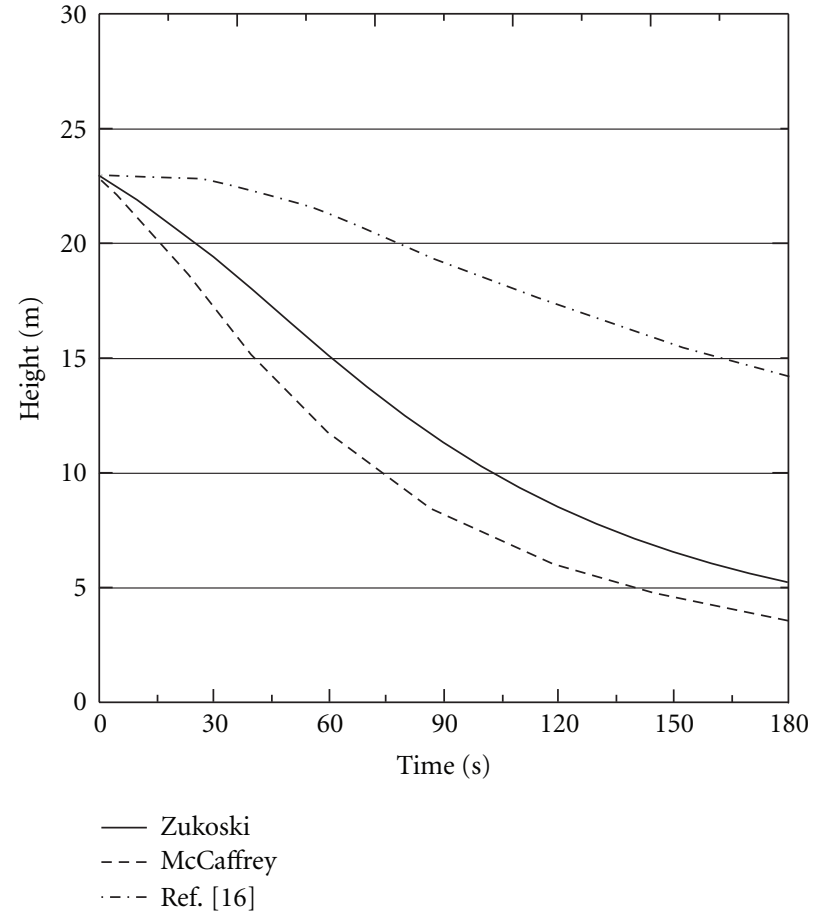

FIGURE 8: The comparison of interface height of smoke layer with heat release rate of 3.0 MW under unsteady fire.

The interface heights of smoke layer of the experiment in [16] under unsteady fire compared with those of McCaffrey and Zukoski plume models with heat release rate of 3.0 MW and 5.0 MW are presented in Figures 8 and 9, respectively. It is seen that the interface heights of the smoke layer derived from McCaffrey's and Zukoski's equation drop much faster than the experimental result, which is presumed to result from steady fire having larger heat release rate and different sources of fire used. It is worth mentioning that Zukoski curves drop initially and McCaffrey curves drop the fastest under both steady fire and unsteady fire.

Large space buildings tend to accumulate great amount of heavy smoke which would easily cause fluctuation of the smoke layer. Smoke production rate is determined by the scale of the fire source and heat release rate. It consequently decides the velocity with which the smoke layer descends. In order to postpone the time the smoke layer descends, smoke exhaust equipment should be installed and the amount of flammable goods should be reduced by avoiding high smokeproducing decoration and furniture in the partitioned space. In case of fire, there should be sufficient time for occupants to evacuate from the fire scene before the smoke layer descends. Therefore a comprehensive fire safety plan should take the installment of fire prevention equipment and evacuation plan into consideration.

\section{Conclusions}

Hot smoke consequently results in serious human injuries and death if it is inhaled and the occupants get burned, 


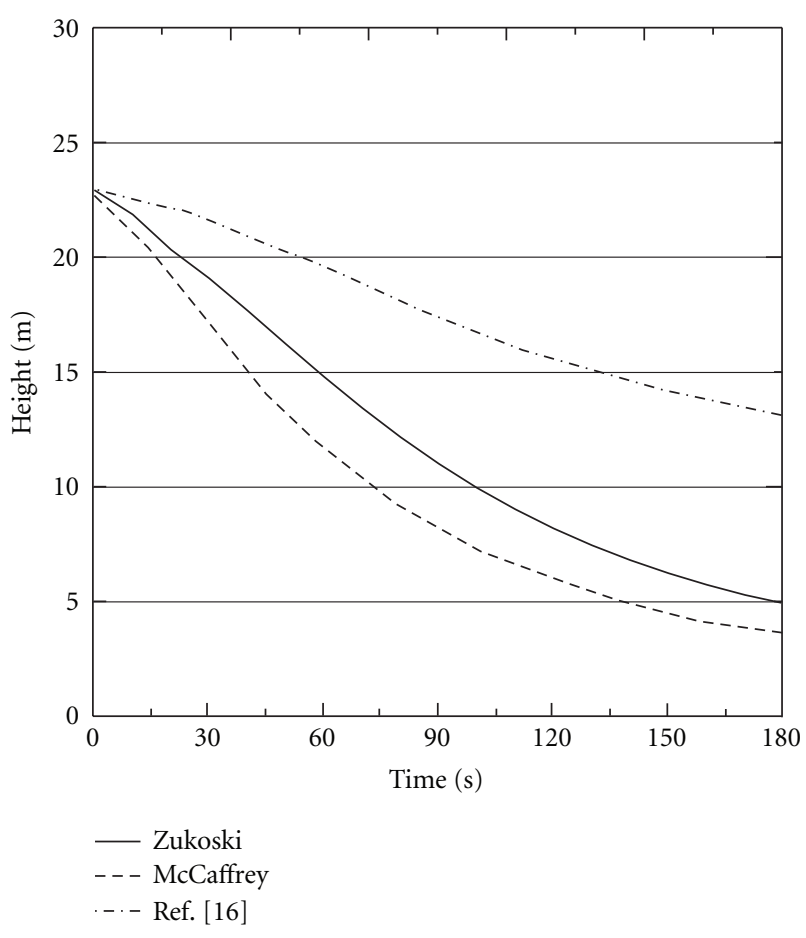

FIGURE 9: The comparison of interface height of smoke layer with heat release rate of 5.0 MW under unsteady fire.

losing visibility, fear, choke in the surroundings lack of oxygen. In this paper, the plume models including Heskestad, McCaffrey, Zukoski, and Thomas were investigated to obtain the equation of smoke layer descent under steady and unsteady fire scenarios. Comparisons with the results using NFPA 92B equations were also made. The conclusions are summarized as follows.

(1) Under the conditions of steady fire and fire source $\dot{Q}=2.0 \mathrm{MW}$, the plume models of Heskestad, McCaffrey, Zukoski, and Thomas yield similar results to the experiments in $[15,16]$. However, the results are quite different under fire source with heat release rate exceeding 3.0 MW, which could be explained by the fact that these plume models do not apply to fire sources with higher heat release rate and different fuels used in the above experiments.

(2) The figure predicted by NFPA 92B is closer to the results derived from Zukoski and Thomas equations under steady fire.

(3) The smoke layer descends faster under steady fire scenario, which may be explained by the fact that the steady fire source reaches the default heat release rate right after ignition while it takes $t$-square time for unsteady fire source to approach the default heat release rate.

(4) The time the smoke layer takes to descend is related to height and heat release rate of the fire source. The higher the fire source is located and the larger the heat release rate is, the more smoke causes the reduction of the time the smoke layer takes to descend.

Nowadays, computer simulation software is the most common tool when calculating the interface height of smoke layer in large space buildings. However, it is time consuming and complicated in calculation as a great number of parameters need to be input, and a lot of information needs to be collected in advance including the condition of the building, type of measurements, density of the sooty gas layer, amount and spices of flammable goods, type of the evacuees, and number of the evacuees NFPA 92B itself has limits when being applied to steady fire and unsteady fire scenarios. For example, in this study the dimensions of the experiments in $[15,16]$ fell out of NFPA 92B applicable conditions. Therefore, how to adopt a simple and accurate evaluation and validation method to assure fire safety and economic efficiency is the primary goal of fire engineering.

\section{References}

[1] L. Y. Cooper, "A Mathematical model for estimating available safe egress time from fires," Fire and Materials, vol. 6, no. 3-4, pp. 135-144, 1982.

[2] F. W. Mowrer, "Enclosure smoke filling revisited," Fire Safety Journal, vol. 33, no. 2, pp. 93-114, 1999.

[3] NFPA, "Standard for Smoke Management System in Malls, Atria, and Large Spaces," NFPA 92B-2005, National Fire Protection Association, Quincy, Mss, USA, 2005.

[4] P. H. Thomas, P. L. Hinkley, C. R. Theobald, and D. I. Simms, "Investigations into the Flow of Hot Gases in Roof Venting," Fire Research Technical Paper 7, HMSO, London, UK, 1963.

[5] E. E. Zukoski, T. Kubota, and B. Cetegen, "Entrainment in fire plumes," Fire Safety Journal, vol. 3, no. 2, pp. 107-121, 1981.

[6] B. J. McCaffrey, "Momentum implications for buoyant diffusion flames," Combustion and Flame, vol. 52, no. 2, pp. 149167, 1983.

[7] G. Heskestad, "Engineering relations for fire plumes," Fire Safety Journal, vol. 7, no. 1, pp. 25-32, 1984.

[8] R. D. Peacock, G. P. Forney, P. Reneke, R. Portier, and W. W. Jones, "CFAST, the consolidated model of fire growth and smoke transport," NIST Technical Note 1299, National Institute of Standards and Technology, Gaithersburg, Md, USA, 1993.

[9] C. L. Shi, Y. Z. Li, R. Huo, B. Yao, W. K. Chow, and N. K. Fong, "Mechanical smoke exhaust for small retail shop fires," International Journal of Thermal Sciences, vol. 44, no. 5, pp. 477-490, 2005.

[10] W. K. Chow, E. Cui, Y. Z. Li, R. Huo, and J. J. Zhou, "Experimental studies on natural smoke filling in atria," Journal of Fire Sciences, vol. 18, no. 2, pp. 84-103, 2000.

[11] W. K. Chow, Y. Z. Li, E. Cui, and R. Huo, "Natural smoke filling in atrium with liquid pool fires up to 1.6 MW," Building and Environment, vol. 36, no. 1, pp. 121-127, 2001.

[12] R. Huo, W. K. Chow, X. H. Jin, Y. Z. Li, and N. K. Fong, "Experimental studies on natural smoke filling in atrium due to a shop fire," Building and Environment, vol. 40, no. 9, pp. 1185-1193, 2005.

[13] K.-C. Chung and H.-S. Tung, "A simplified model for smoke filling time calculation with sprinkler effects," Journal of Fire Sciences, vol. 23, no. 4, pp. 279-301, 2005. 
[14] N. B. Kaye and G. R. Hunt, "Smoke filling time for a room due to a small fire: the effect of ceiling height to floor width aspect ratio," Fire Safety Journal, vol. 42, no. 5, pp. 329-339, 2007.

[15] K. S. Yang, "A study on the experimental investigation of the performance-based management system design of a building with atrium and large space," Architecture Research Institute, Taiwan, 2000.

[16] K. S. Yang, The Full-Scale Hot Smoke Test and Validation of Passive Smoke Management System in Large Space Building, M.S. thesis, Architecture Research Institute, Taiwan, 2004.

[17] G. Heshestad, Fire Plume, Flame Height, and Air Entrainment, SFPE Handbook of Fire Protection Engineering, National Fire Protection Association, Quincy, Mass, USA, 3rd edition, 2002.

[18] B. M. Cetegen, E. E. Zukoski, and T. Kubota, "Entrainment in the near and far field of fire plume," Combustion Science and Technology, vol. 39, pp. 305-331, 1984. 

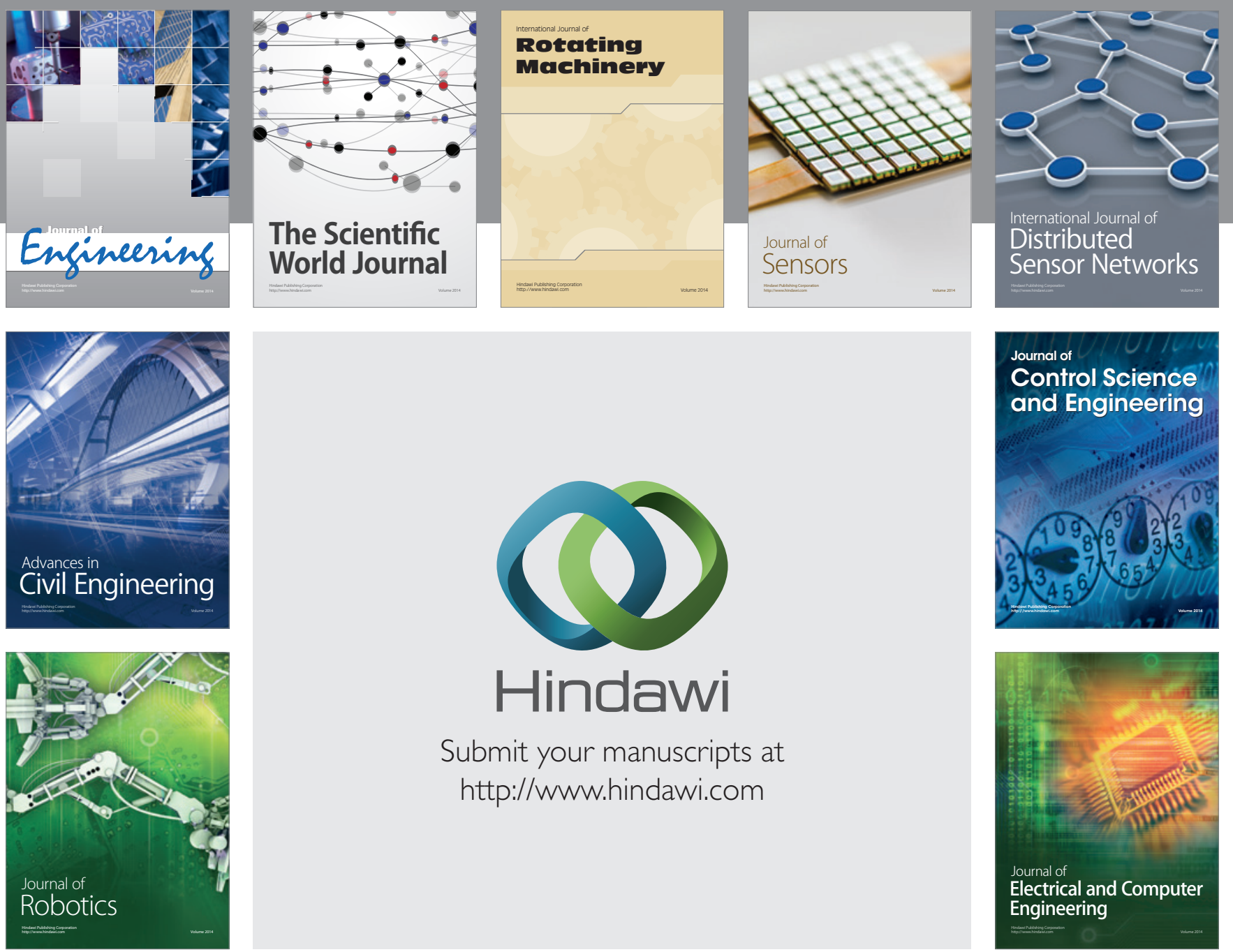

Submit your manuscripts at

http://www.hindawi.com
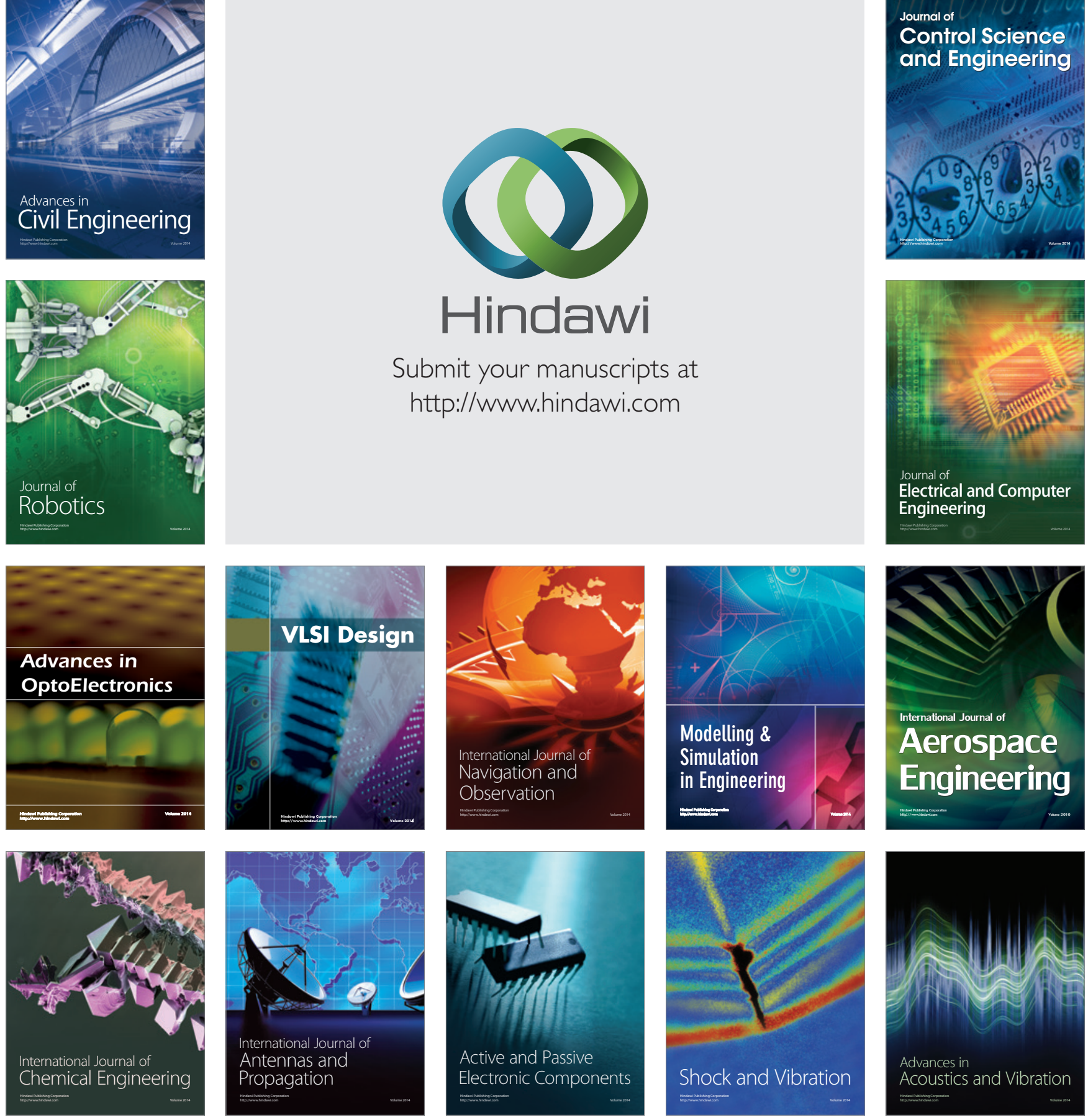